\title{
Araştırma Makalesi/Research Article (Original Paper) \\ Patateste (Solanum tuberosum L.) in vitro Mikrotuberizasyon Üzerine Fotoperiyot, Jasmonik Asit ve Aktif Kömürün Etkileri
}

\author{
Seray KENAR ${ }^{1}$, Gökçen BAYSAL FURTANA² ${ }^{2}$, Ş. Şebnem ELLİALTIOĞLU ${ }^{3}$ \\ Rukiye TIPIRDAMAZ ${ }^{1}$
}

\author{
${ }^{1}$ Hacettepe Üniversitesi, Fen Fakültesi, Biyoloji Bölümü, Beytepe, Ankara, Türkiye \\ ${ }^{2}$ Gazi Üniversitesi, Fen Fakültesi, Biyoloji Bölümü, Teknikokullar, Ankara, Türkiye \\ ${ }^{3}$ Ankara Üniversitesi, Ziraat Fakültesi, Bahçe Bitkileri Bölümü, Dışkapı, Ankara, Türkiye \\ *e posta: tuz@hacettepe.edu.tr; Tel:+90(312)2978005; Fax: +90 (312) 2992028
}

Özet: Bu çalışmada, ekonomik değeri olan Solanum tuberosum L. cv. Marfona'da in vitro mikrotuber oluşumu üzerinde fotoperiyot ile ortama ilave edilen Jasmonik asit (JA), aktif kömür (AC) ve agarın etkileri araştırılmıştır. $\mathrm{Bu}$ amaçla çalışma 4 aşamada gerçekleştirilmiştir: Tuberlerden sürgün oluşumu, in vitro sürgün ucu kültürü, mikroçoğaltım ve mikrotuberizasyon. Sürgün ucu kültürü ile in vitro çoğaltılan bitkilerden alınan tek boğum eksplantları JA $\left(0.0-0.2 \mathrm{mg} \mathrm{L}^{-1}\right)$, agar $(\% 0.5, \% 0.7)$ ve $\mathrm{AC}(0, \% 0.2)$ içeren çift fazlı Murashige and Skoog (MS) ortamlarında 2 farklı fotoperiyotta kısa gün (8/16 saat aydınlık/karanlık veya sürekli karanlık) kültüre alınmıştır. En yüksek mikrotuber verimi (\%137) ve en yüksek ortalama mikrotuber ağırlığı $(183 \mathrm{mg}) ; \% 0.2 \mathrm{AC}, \% 0.5$ agar içeren çift fazlı MS ortamında ve karanlıkta elde edilmiştir. AC'nin mikrotuber oluşumu üzerindeki olumlu etkisinin JA'den daha fazla olduğu ve AC'nin karanlıkta daha etkili olduğu belirlenmiş̧ir.

Anahtar kelimeler: Patates (Solanum tuberosum L.), in vitro, Mikrotuberizasyon, Çift fazlı ortam, Jasmonik Asit, Aktif Kömür.

\section{The Effects of Photoperiod, Jasmonic Acid and Activated Charcoal on in vitro microtuberization in Potatoes (Solanum tuberosum L.)}

\begin{abstract}
In this study, effects of added agar, jasmonic acid (JA), activate charcoal (AC) with photoperiod regime on in vitro microtuber formation in Solanum tuberosum cv. Marfona. Study has actualized as 4 main steps; shoot formation of the tubers of $S$. tuberosum, in vitro shoot-tip culture, micropropagation and microtuberization. The effects of JA $\left(0.0-0.2 \mathrm{mgL}^{-1}\right)$, agar $(0.5 \%$ or $0.7 \%)$, $\mathrm{AC}(0$ and $0.2 \%)$ microtuberization were investigated. The highest microtuber yield $(137 \%)$ and the highest microtuber average $(183 \mathrm{mg} /$ tuber $)$ were obtained at the double-layer Murashige and Skoog (MS) medium which contains $0.2 \% \mathrm{AC}, 0.5 \%$ agar under darkness conditions. It has been determined that positive effect of $\mathrm{AC}$ on microtuber formation is higher than JA. AC was found much more effective in the dark.
\end{abstract}

Key words: Potato (Solanum tuberosum L.), in vitro, Microtuberization, Double-layer medium, Jasmonic acid, Activated charcoal.

\section{Giriş}

Sürgün ucu kültürü ile başlayan ve in vitro'da çoğaltılan virüssüz bitkiciklerden üretilen mikrotuberlerin patates tohumluğu üretiminde önemli avantajları olduğu kabul edilmektedir. Yapılan çalışmalarda in vitro mikrotuber oluşumu bir dizi faktöre dayandırılmaktadır. Bunlar arasında besin ortamı bileşimi (aktif kömür, sakkaroz konsantrasyonu vs), büyüme düzenleyicileri (Giberellik asit, absisik asit, etilen, trimetilamonyum klorid, jasmonik asit), sıcaklık, fotoperiyot, 1şık şiddeti gibi çevresel faktörler ve genotip faktörü sayılabilmektedir (Chevre ve ark. 1983; Garner ve Blake 1989; Bhatia ve ark. 1992; Beyazova 1999; Öztürk 2003; Kim ve ark. 2005; Jasik ve Klerk 2006). Ancak yapılan araştırmalar, jasmonik asit (JA) ve metil esterlerinin tuber uyartımındaki etkisi konusunda yoğunlaşmıştır (Pruski ve ark. 2002; Zhang ve ark. 2006; Rayirath ve ark. 2011). JA, patojen saldırlarında bitkinin savunma mekanizmasını harekete geçirmesinin yanı sıra birçok fizyolojik ve gelişim sürecini de (kök büyümesi, tuberizasyon, yaşlanma, polen gelişimi gibi) düzenlemektedir. Jasmonik asit (JA) ile aktif kömürün (AC) birbiriyle ve çevresel 
faktörlerle olan etkileşimlerinin tuber gibi vejetatif depo organlarının oluşumu ve gelişimi üzerinde etkili olduğu vurgulanmaktadır (Phillips ve ark. 1996; Burrows ve Tyrl 2001). Ancak JA'in mikrotuber oluşumu üzerindeki etkileri ve diğer büyüme düzenleyicileriyle olan ilişkileri hakkındaki bilgiler tam olarak aydınlatılamamıștır (Jasik ve Mantell 2000; Zhang ve ark. 2006; Rayirath ve ark. 2011). Herhangi bir ticari mikrotuber üretimine JA'in dahil edilebilmesi için, tuberizasyon üzerindeki etkisi hakkında daha fazla bilgiye gereksinim duyulmaktadır.

Çalışmada Solanum tuberosum L. cv. Marfona'da in vitro mikrotuber oluşumu üzerinde çift fazlı MS ortamına ilave edilen agar (\%0.5 veya \%0.7), AC ( 0 ve \%0.2), JA $\left(0.0\right.$ ve $\left.0.2 \mathrm{mg} \mathrm{L}^{-1}\right)$, ve fotoperiyodun (8/16 saat aydınlık/karanlık- kısa gün veya karanlık) etkileri ve birbirleri ile ilişkisi araştırılmıştır.

\section{Materyal ve Yöntem}

S. tuberosum yumrularının in vivo'da sürgün vermesi, in vitro sürgün ucu kültürü yoluyla mikroçoğaltım ve mikrotuberizasyon aşamalarında Kenar ve Tıpırdamaz (2012), Kenar (2013) kullandığı yöntemler (ortamlar ve koşullar) kullanılmıştır. Çalışma 4 aşamada gerçekleştirilmiş̧ir:

Tuberlerden sürgün oluşumu aşaması: Yazlık hasat döneminde (Temmuz-Ekim) toplanan S. tuberosum L. cv. Marfona yumruları, perlit doldurulmuş saksılara dikilerek $30-35^{\circ} \mathrm{C}$ sıcaklık, $\% 60-65$ oransal nem, 145 $\mu \mathrm{mol} \mathrm{m} \mathrm{m}^{-2} \mathrm{~s}^{-1} 1$ ş̧ı şiddeti ve 16/8 saat aydınlık/karanlık koşullara ayarlanmış iklim odasında bekletilmiş ve yumrulardan 4 hafta sonunda sürgün oluşumu sağlanmıştır (Şekil 1a).

In vitro sürgün ucu kültürü aşamasl: Tuberlerden elde edilen sürgün uçları \%70'lik alkolde $1 \mathrm{dk}$ süreyle çalkalandıktan sonra, içine 2 damla Tween-20 damlatılmış \%10'luk $\mathrm{NaOCl}$ çözeltisinde 7-8 dk bekletilmiş ve 3 kere distile su ile sterilize edilmiştir. Sterilize edilen sürgün uçlarından, $30 \mathrm{~g} \mathrm{~L}^{-1}$ şeker, $7 \mathrm{~g} \mathrm{~L}^{-1}$ agar, 0.2 $\mathrm{mg} \mathrm{L}^{-1} \mathrm{GA}_{3}, 0.2 \mathrm{mg} \mathrm{L}^{-1}$ Kinetin, $0.2 \mathrm{mg} \mathrm{L}^{-1} \mathrm{IAA}$ ve $100 \mathrm{mg} \mathrm{L}^{-1}$ myo-inositol ilave edilmiş pH's1 5.8 olan DMS besin ortamlarında $20-22{ }^{\circ} \mathrm{C}$ sıcaklık, $145 \mu \mathrm{mol} \mathrm{m}^{-2} \mathrm{~s}^{-1}$ şiddetinde 1 şı ve $16 / 8$ saat aydınlı/karanlık fotoperiyotta 2-2.5 ay sonunda patates bitkicikleri elde edilmiştir (Şekil 1b).

Mikroçoğaltım aşaması: Sürgün ucu kültürü ile elde edilen bitkiciklerden alınan tek boğum eksplantlarının çoğaltımı, $1.0 \mathrm{mg} \mathrm{L}^{-1} \mathrm{IAA}$ ve $1.0 \mathrm{mg} \mathrm{L}^{-1} \mathrm{BAP}$ ile $7 \mathrm{~g} \mathrm{~L}^{-1}$ agar, $30 \mathrm{~g} \mathrm{~L}^{-1}$ şeker, $60 \mathrm{mg} \mathrm{L}^{-1}$ myo-inositol, $0.4 \mathrm{mg}$ $\mathrm{L}^{-1}$ thiamine, $1 \mathrm{~g} \mathrm{~L}^{-1}$ pridoksin ilave edilmiş $\mathrm{pH}$ 's 5.8 olan çift fazlı MS (DMS) besin ortamı içeren tüplere dikilerek, $22{ }^{\circ} \mathrm{C}$ sıcaklık ve $16 / 8$ saat aydınlık/karanlık fotoperiyotta $145 \mu \mathrm{mol} \mathrm{m}^{-2} \mathrm{~s}^{-1}$ 1şık şiddetinde kontrollü iklim odasında yapılmıştır.

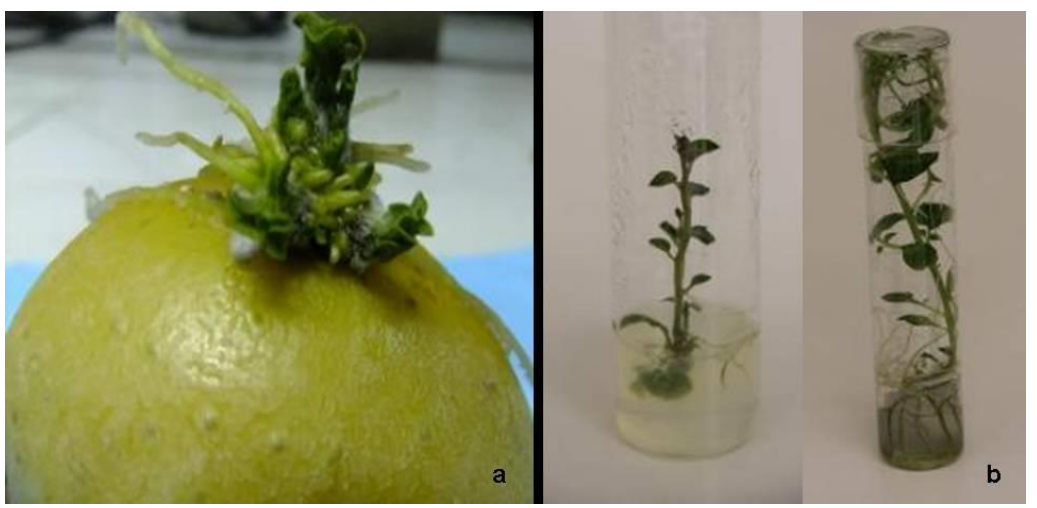

Şekil 1. a) Tuberler üzerinde oluşan 3-4 haftalık sürgün,

b) Sürgün ucu kültüründen elde edilen 3-4 haftalık bitkiler (solda), 6 haftalık bitkiler (sağda)

Mikrotuberizasyon aşaması: In vitro'da çoğaltımı yapılmış tek boğum (single node) eksplantları, JA (0.0, $\left.0.2 \mathrm{mgL}^{-1}\right), \mathrm{AC}(\% 0.0,0.2)$ ve agarın $(\% 0.5, \% 0.7)$ farklı kombinasyonlarını içeren çift fazlı MS (DMS) ortamlarında $\left(80 \mathrm{gL}^{-1}, \mathrm{pH} 5.7\right), 22-25^{\circ} \mathrm{C}$ sıcaklık, $145 \mu \mathrm{mol} \mathrm{m}^{-2} \mathrm{~s}^{-1}$ 1şık şiddetinde kısa gün $(8 / 16$ saat aydınlık/karanlık) ve sürekli karanlık ışıklanma rejimlerinde 8 hafta inkübe edilerek mikrotuber oluşumu üzerindeki etkileri belirlenmiştir (Beyazova 1999; Tican ve ark. 2008; Nistor ve ark. 2010). 
Mikrotuberlerin çoğaltımı: Elde edilen mikrotuberler 2:1 torf-perlit karışımı içeren küçük saksılara dikilerek, 22-24 ${ }^{\circ} \mathrm{C}$ sicaklık, $\% 60$ oransal nem, $145 \mu \mathrm{mol} \mathrm{m} \mathrm{m}^{-2} \mathrm{~s}^{-1}$ 1ş1k şiddetinde ve 16/8 saat aydınlık/karanlık fotoperiyoduna ayarlanmış iklim odasına yerleştirilmiş ve gelişmeleri takip edilmiştir.

Deneme 5 tekerrürlü olarak planlanmış ve her tekerrürde 10 eksplant bulunan 50'şer ml besin ortamı içeren kavanozlara $(6.5 \times 7.5 \mathrm{~cm})$ eksplantlar dikey olarak dikilmiştir. Bu süre sonunda tek boğumlardan elde edilen eksplant sayısı, mikrotuber elde edilen eksplant sayısı, mikrotuber sayısı, mikrotuber ağırlıkları, eksplant verimi (mikrotuber elde edilen eksplant sayıs1/toplam eksplant sayısı) mikrotuber verimleri (mikrotuber sayısı/toplam eksplant sayısı) belirlenmiştir. Verimler, çizelgede yüzde (\%) olarak belirtilmiştir.

Verilerin istatistiksel analizleri SPSS paket programı kullanılarak yapılmıştır. Varyans analizleri ve istatistiksel testler sonucunda her bir değişken için en küçük önemli farklılıklar (LSD) \%5 önem aralıklarında hesaplanmıştır.

Tüm grup karşılaştırmalarında varyans analizi için Oneway-ANOVA, grup içi ve gruplar arası karşılaştırmalarda Duncan Çoklu Karşılaştırma Testi kullanılmıştır (Sokal ve Rohlf 1995).

\section{Bulgular}

Farklı düzeylerdeki AC, JA, agar kombinasyonları ve fotoperiyodun mikrotuber oluşumu üzerine etkileri ile ilgili bulgular Çizelge 1 'de gösterilmiştir.

Çizelge 1. Ortam içeriği ve fotoperiyodun mikrotuber oluşumuna ve ağırlığına olan etkisi ile ilgili veriler.

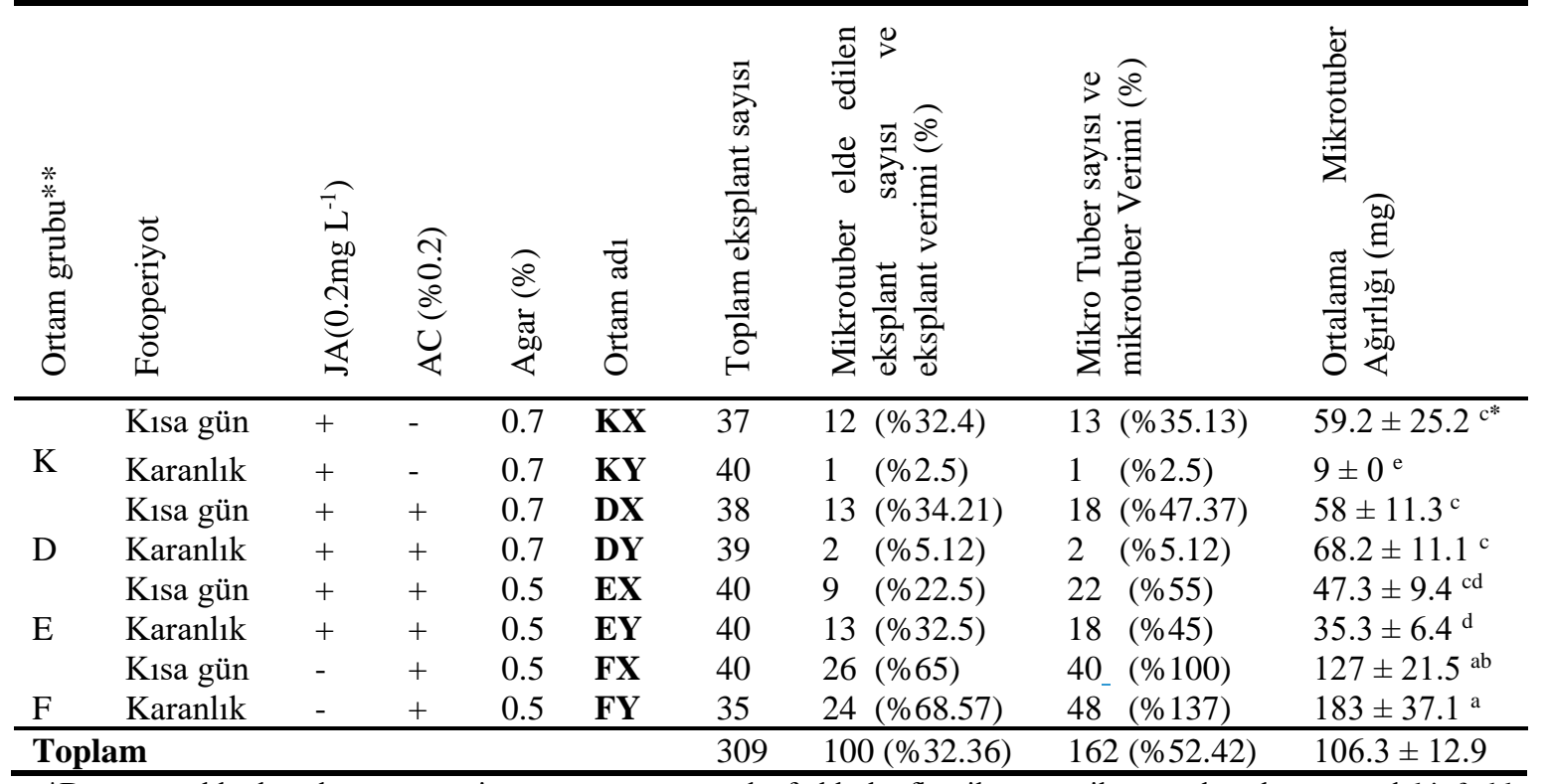

*Duncan çoklu karşılaştırma testine göre aynı sütunda farklı harfler ile gösterilen ortalamalar arasındaki farklar önemlidir ( $\mathrm{p}<0.05)$. ${ }^{* *} \mathbf{K X}$ (Kısa gün $-0.2 \mathrm{mgL}^{-1} \mathrm{JA}+\% 0.7$ Agar), KY (Karanlık $-0.2 \mathrm{mgL}^{-1} \mathrm{JA}+\% 0.7$ Agar), DX (Kısa gün $-0.2 \mathrm{mgL}^{-1} \mathrm{JA}+\% 0.2 \mathrm{AC}+\% 0.7 \mathrm{agar}$ ), DY (Karanlık $-0.2 \mathrm{mgL}^{-1} \mathrm{JA}+\% 0.2 \mathrm{AC}+\% 0.7$ agar), EX (Kisa gün $-0.2 \mathrm{mgL}^{-1} \mathrm{JA}+\% 0.2 \mathrm{AC}+\% 0.5 \mathrm{agar}$ ), EY (Kısa gün $-0.2 \mathrm{mgL}^{-1} \mathrm{JA}+\% 0.2 \mathrm{AC}+\% 0.5 \mathrm{agar}$ ), FX (Kisa gün $\% 0.2 \mathrm{AC}+\% 0.5$ agar), FY (Karanlık - \%0.2 AC+\%0.5 agar)

Varyans analiz sonuçları incelendiğinde, ortam bileşimi (JA, AC, Agar) ve fotoperiyod uygulamalarının mikrotuber ağırlığına etkisi istatistik olarak önemli bulunmuştur $(\mathrm{p}<0.05)$. Eksplant verimi (mikrotuber elde edilen eksplant sayıs1/toplam eksplant sayısı) ile mikrotuber verimi (mikrotuber sayısı/toplam eksplant sayısı) arasındaki ilişkinin genellikle doğru orantılı olarak arttığı gözlenmiştir. Buna göre en yüksek mikrotuber verim yüzdesine sahip olan FY (Karanlık, \%0.2 AC+\%0.5 agar) (\%137) ve FX (Kısa gün, $\% 0.2 \mathrm{AC}+\% 0.5$ agar) (\%100) ortam gruplarının mikrotuber elde edilen eksplantlarının verim yüzdesinin de yüksek olduğu (FY: \% 68.57 ve FX: \%65); düşük mikrotuber verimine sahip olan KY (Karanlık, $0.2 \mathrm{mgL}^{-1}$ $\mathrm{JA}+\% 0.7$ Agar) ve DY (Karanlık, $0.2 \mathrm{mgL}^{-1} \mathrm{JA}+\% 0.2 \mathrm{AC}+\% 0.7$ agar) ortam gruplarının mikrotuber elde edilen eksplantlarının verim yüzdesinin de düşük olduğu (KY: \%2.5 ve DY: \%5.12) görülmektedir (Çizelge 1). Ayrıca eksplantların verdiği tuber sayısına göre hesaplanan ve oransal olarak ifade edilen verimin, JA 
(0.2 $\left.\mathrm{mgL}^{-1}\right)$ bulunan ortam gruplarında ve kısa gün fotoperiyodunda, karanlıkta tutulan kültürlere nazaran daha yüksek olduğu belirlenmiştir. Bunun sonucu olarak JA'in etki mekanizmasında 1şığın etkili olduğu düşünülmüştür. Diğer yandan AC (aktif kömür) (\% 0.2) tek başına ortamda bulunduğunda (F grubu) karanlıkta daha yüksek verim elde edildiği gözlenmiştir. Dolayısıyla AC'nin karanlıkta daha etkili bir şekilde mikrotuber oluşum mekanizmasını desteklediği düşünülmüştür.

Denemelerdeki ortam bileşimi ve fotoperiyot ile mikrotuber ağırlığı arasındaki ilişkinin önemli olduğu görülmektedir $(\mathrm{p}<0.05)$. Mikrotuber ağırlığı bakımından en yüksek değerler sırasıyla FY (Karanlık, \% 0.2 AC, \%0.5 Agar) (183 mg) ve FX (Kısa gün, \%0.2 AC, \%0.5 Agar) (127 mg) gruplarında elde edilmiştir (Şekil 2). Bu sonuca göre sadece aktif kömür (AC) katılmış besin ortamlarının tuber ağırlığını artırıcı yönde etkisi olduğu tespit edilmiştir. Tek başına fotoperiyot, mikrotuber ağırlı̆̆ üzerinde etkili olarak gözlemlenmemiştir. Denemedeki en yüksek mikrotuber verimi (\%137) ve en yüksek ortalama mikrotuber ağırlığı $(183 \mathrm{mg}) ; \% 0.2 \mathrm{AC}$ ve \%0.5 agar içeren çift fazlı MS ortamında ve karanlık inkübasyon koşullarında elde edilmiştir. Şekil 2'de denemelerde olumlu sonuç veren FY kodlu uygulamaya ait görünümlere yer verilmiştir/
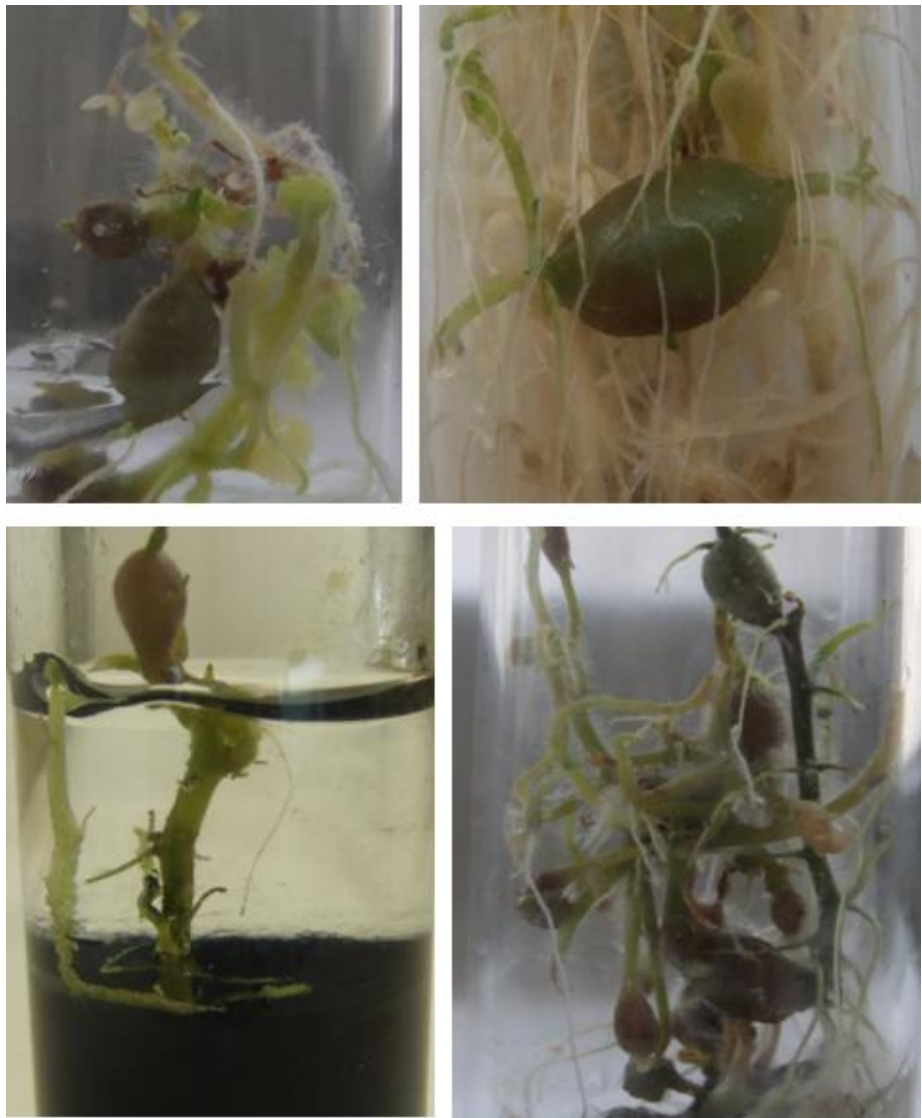

Şekil 2. FY (Karanlık, \%0.2 AC+ \%0.5 agar içeren) ortamında oluşan mikrotuberler.

Tohumluk patates olarak kullanılması için üretilen mikrotuberler dış koşullara aktarılarak gelişimleri incelendiğinde mikrotuber ağırlığı daha fazla olan, yani daha iri mikrotuberlerden bitki gelişiminin de daha hızlı olduğu gözlenmiştir. Şekil 3'te mini yumrulardan gelişen bitkilerin dış koşullara alıştırılması aşaması ve sağlıklı yeni bir bitki görülmektedir. 

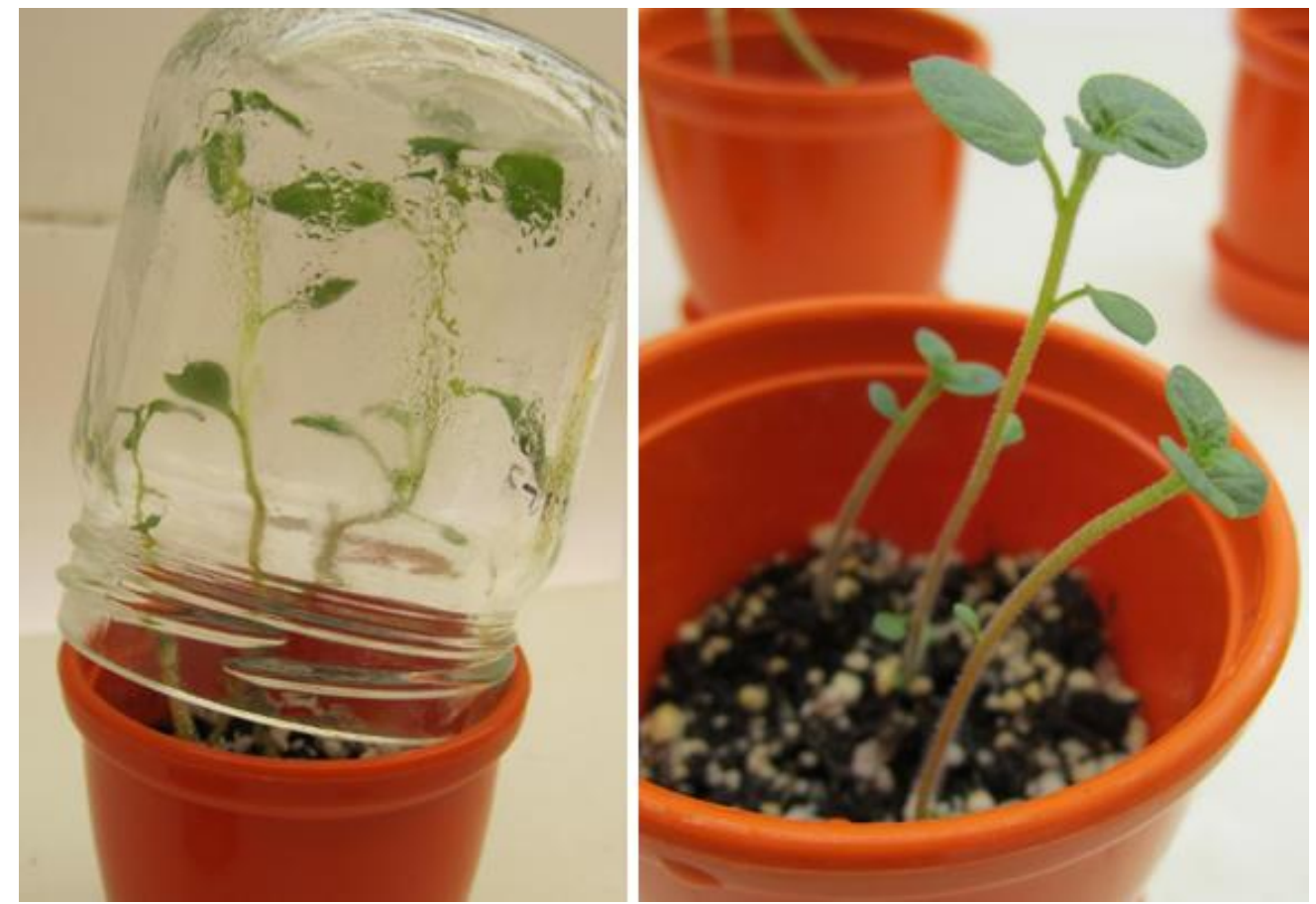

Şekil 3. Saksılara dikilen in vitro yumrulardan gelişen bitkiciklerin diş koşullara alıştırılması ve mikrotuberlerden oluşan 3-4 haftalık bitkiler.

\section{Tartışma ve Sonuç}

Çalışmamızda, tuberlerden elde edilen sürgün uçları, $30 \mathrm{~g} \mathrm{~L}^{-1}$ şeker, $7 \mathrm{~g} \mathrm{~L}^{-1}$ agar, $0.2 \mathrm{mg} \mathrm{L}^{-1} \mathrm{GA}_{3}, 0.2 \mathrm{mg} \mathrm{L}^{-1}$ Kinetin, $0.2 \mathrm{mg} \mathrm{L}^{-1}$ IAA ve $100 \mathrm{mg} \mathrm{L}^{-1}$ myo-inositol ilave edilmiş pH's 5.8 olan çift fazlı MS (DMS) besin ortamlarında, $20-22{ }^{\circ} \mathrm{C}$ sıcaklık, $145 \mu \mathrm{mol} \mathrm{m}^{-2} \mathrm{~s}^{-1}$ şiddetinde 1 şı ve $16 / 8$ saat aydınlık/karanlık fotoperiyotta iklim odasında 2-2.5 ay sonunda bitkicikleri oluşturmuştur. Benzer hormonları kullanmış olan Sangwan ve ark. (1987) ise en iyi sürgün gelişimini $0.1 \mathrm{mg} \mathrm{L}^{-1}$ Kinetin, $0.1 \mathrm{mg} \mathrm{L}^{-1} \mathrm{GA}_{3}$ ve $0.5 \mathrm{mg} \mathrm{L}^{-1}$ IAA içeren MS besin ortamında elde etmişlerdir. Diğer yandan Zhang ve Zhou (2005), ortama $10 \mathrm{mg} \mathrm{L}^{-1} \mathrm{IAA}$ ve $0.5 \mathrm{mg} \mathrm{L}^{-}$ ${ }^{1} \mathrm{GA}_{3}$ ilave etmenin sürgün gelişimini teşvik ettiğini belirlemişlerdir.

Çalışmamızda gerek in vivo'da tuberlerden sürgün oluşumu ve gerekse in vitro'da sürgün ve bitki gelişimi, $16 / 8$ saat aydınlık/karanlık fotoperiyotta gerçekleştirilmiștir. Mikrotuberizasyon denemelerinde JA $(0.2 \mathrm{mg}$ $\left.\mathrm{L}^{-1}\right)$, AC (\%0.2) ve agarın $(\% 0.5, \% 0.7)$ farklı dozların içeren çift fazlı ortamlarda kısa gün $(8 / 16$ saat aydınlık/karanlık) ve sürekli karanlık fotoperiyotlarında inkübe edilen tek boğum eksplantlarından mikrotuber oluşumu incelenmiştir. Mikrotuber oluşumu üzerine en olumlu etki yapan uygulamanın; \% 0.2 aktif kömür (AC) ve \%0.5 agar içeren çift fazlı MS besin ortamı ve karanlık inkübasyonu olduğu belirlenmiştir. Mikrotuber denemelerinde besin ortamlarına \%8 sukroz ilave edilmiştir.

Patateste doğal koşullarda tuber oluşumu, çevresel ve hormonal kontrol altında olan bir süreçtir. Aynı şekilde, in vitro büyüme koşullarında da birçok faktör mikrotuber oluşumunu etkilemektedir. In vitro mikrotuberizasyonu etkileyen önemli değişkenler; ortamdaki şeker konsantrasyonu, ortama ilave edilen büyüme düzenleyicilerin cinsi ve dozu, ortam tipi, kültür şekli ve patates kültürlerinin inkübe edildiği ortam koşulları (sıcaklık, fotoperiyot) olarak belirtilmektedir (Castro ve ark. 2000; Romanov ve ark. 2000; Taiz ve Zeiger 2008). Çalışmamızda Aslam ve Iqbal (2010)'in sonuçlarına benzer olarak mikrotuberizasyon ortamına ilave edilen \%8 sukroz, tuber oluşumunu olumlu yönde desteklemiş̧ir. Aynı şekilde Khuri ve Moorby (1995), yüksek karbonhidrat seviyesinin ve böylece kolayca bünyeye alınabilen ve mikrotuber gelişimi için nişastaya dönüştürülebilen iyi bir karbon kaynağı sağlamasının, in vitro tuberler için kesintisiz bir nişasta sentezi sağladığını belirtilmişlerdir. Araştırıcılar yüksek dozda kullanılan sukrozun etkisiyle oluşan yüksek ozmotik potansiyelin de tuber oluşumunu desteklediğini bildirmişlerdir.

Vreugdenhil ve ark. (1998), kültür ortamının kompozisyonuna bağlı olarak, in vitro kültüre alınmış aksiller tomurcukların; \%8 sukroz varlığında tuber oluşturduğunu göstermiştir. Araştırmada gelişimin farklı 
evrelerinde şekerin nişastaya dönüşümüne dahil olan içsel şeker, nişasta ve enzim seviyelerinde farklar olduğu; tuber oluşumu sırasında glukoz ve fruktoz miktarının azaldığı, diğer yandan sukroz sentaz, fruktokinaz ve ADP-glukoz pirofosforilaz aktivitelerinin arttığı belirlenmiştir.

Patateste tuber oluşumu üzerindeki en önemli çevresel faktörlerden birisi kuşkusuz fotoperiyottur. Kısa günlerin, tuber oluşumunu teşvik ettiği ve bu etkisinin $\mathrm{GA}_{3}$ seviyesindeki azalma ile ilişkili olduğu bilinmekte ve ayrıca mikrotuberlerin oluşumunda, genotipin ve fotoperiyodik uygulamaların etkili olduğu belirtilmektedir (Seabrook ve ark. 1993; Taiz ve Zeiger 2008).

Carrera ve ark. (2000) tarafindan yabani patateslerde tuberlerin sadece kısa günlerde oluştuğu ve bu tuber oluşumunun gibberellin uygulandığında önlenebildiği gösterilmiştir. Gibberellin-fotoperiyot etkileşiminin patateste mikrotuberizasyonun kontrolüne etkisinin incelendiği diğer bir çalışmada (Martinez-Garcia ve ark. 2002) S. tuberosum ssp. andigena bitkilerinin, tuber oluşumu için kısa gün fotoperiyoduna ihtiyaç duyduğu ve bu sürecin gibberellinler tarafından da kontrol edildiği teyit edilmiş̧ir.

Jasmonik asidin tuber indükleyici bir sinyal olarak taşındığı, tuber oluşumunda ve gelişiminde yer aldığı belirtilmektedir (Jackson ve Willmitzer 1994). Ortamda JA bulunduğunda $\mathrm{GA}_{3}$ 'in tuberizasyon üzerindeki inhibe edici etkisinin ortadan kalktığı gözlenmiştir. Bunun JA'in GA'lerin etkisini antagonize etmesiyle ilişkili olabileceği düşünülmüştür (Jackson 1999; Castro ve ark. 2000). Benzer olarak, Kenar (2013) tarafından yapılan ve $\mathrm{JA}, \mathrm{GA}_{3}$ ile ortam tipinin mikrotuberizasyona etkilerinin araştıııldığı çalışmada; tek boğum eksplantlarından en iyi mikrotuber oluşumunun, kısa gün fotoperiyodunda (8/16 saat aydınlık/karanlık) $0.2 \mathrm{mg} \mathrm{L}^{-1} \mathrm{JA}$ içeren ve $\mathrm{GA}_{3}$ içermeyen çift fazlı MS ortamında gerçekleştĭgi görülmüş ve bunun $\mathrm{JA}$ ile $\mathrm{GA}_{3}$ arasındaki antagonistik etkileşimin sonucu olarak ortaya çıktığı belirtilmiştir. Ayrıca Jasik ve Mantell (2000), JA etkisini 3 yam (Dioscorea) çeşidi üzerinde de gözlemlemiş olup ortama JA ilavesinin mikrotuberizasyonu desteklediğini kanıtlamıştır.

Pruski ve ark. (2002), ortamda JA (2.5 mM) bulunduğunda daha fazla sayıda ve daha ağır mikrotuberler elde etmişlerdir. Patateste tuberizasyon, stolondaki sub-apikal meristemin genişlemesiyle başlamakta ve jasmonatlar stolonların boyuna uzamasının önüne geçerek sub-apikal meristem genişlemesini teşvik etmektedir. Yapılan bir çalışmada (Takahashi ve ark. 1994), ortama ilave edilen 3 x $10^{-5}$ M JA'in tuber ağırlığını iki katına çıkardığı belirlenmiştir.

Çalı̧̧mamızda Pruski ve ark. $(2001,2002)$ 'nın sonuçlarına benzer olarak, tuber verimi üzerine ortam içeriği ve fotoperiyot etkisi incelendiğinde JA içeren besin ortamlarında, kısa gün fotoperiyodu altında karanlık fotoperiyoda göre daha yüksek değerler elde edilmiştir. Diğer çalışmalardan elde edilen bulgularla, denemelerimizde bulunan sonuçlar birbirini destekler nitelikte olup JA ile 1şılanma arasında pozitif bir ilişki olduğuna işaret etmektedir. Patateste mikrotuber oluşumu üzerine fotoperiyodun etkisi de belirgindir. Garner ve Blake (1989), Khuri ve Moorby (1996) ile Ranalli (1997) yaptıkları çalışmalarda, 8 saat aydınlık fotoperiyodun, mikrotuber üretimi açısından karanlık fotoperiyottan daha uygun olduğunu belirtmişlerdir. Buna karşın Pruski ve ark. (2002), sürekli karanlıkta inkübe edilen kültürlerde, aydınlık/karanlık fotoperiyotlara göre daha erken tuber oluşumu meydana geldiğini bildirmişlerdir. Ayrıca, Nistor ve ark. (2010) ve Hoque (2010) mikrotuber oluşumunun teşviki ve gelişiminde, karanlıkta inkübasyonun en iyi sonuçları verdiğini ifade etmektedirler. Çalışmamızdan elde edilen bulgular da bu literatür bildirişleri ile uyum içindedir.

Mikrotuber denemelerinde aktif kömür (AC) (\%0.2) tek başına ortamda bulunduğunda (F grubu) karanlık fotoperiyotta, daha yüksek verim ve daha ağır mikrotuberler elde edildiği gözlenmiştir. Dolayısıyla AC'nin karanlıkta daha etkili bir şekilde mikrotuber oluşum mekanizmasını desteklediği kanısına varılmııstır.

Mikrotuber denemelerinde çift fazlı ortamın katı fazında bulunan agar miktarı (\%0.5 ve \%0.7) ile mikrotuber verimi ve mikrotuber ağırlı̆̆ arasındaki ilişkinin önemli olmadığı görülmüştür (Çizelge 1). Benzer olarak, Tianyu ve ark. (2006) yaptıkları çalışmada ortamdaki agar miktarının tuber indüklenmesini etkilemediğini gözlemlemişlerdir. Mikrotuber denemelerinde AC'nin tek başına ortamda bulunduğu gruplarda (FX ve FY) mikrotuber verimi (FX: \%100, FY: \%137) ve mikrotuber ağırlı̆̆ (FX: 127 mg, FY: $183 \mathrm{mg}$ ) diğer gruplara göre önemli ölçüde daha yüksek olduğu tespit edilmiştir. Benzer olarak Beyazova (1999) da, ortama aktif kömür eklenmesiyle tüp başına oluşan mikrotuber sayılarında fazla bir değişiklik olmadıysa da mikrotuber ağırlıklarının önemli ölçüde arttı̆̆ını belirlemiştir. 
Besin ortamları içerisinde bulunabilen veya bitki dokularının salgıladığı toksik (muhtemelen fenolik) bileşiklerin aktif kömür tarafından adsorbe edilebildiği ve böylece doku farklılaşması üzerine inhibitör etki yapabilecek maddelerin etkisini ortadan kaldırabileceği görüşü, araştırıcılar tarafından rapor edilmektedir (Pierik 1987). Aktif kömürün, patateste mikrotuber oluşumunu teşvik ettiği birçok araştırıcı tarafından öne sürülmüş ve mikrotuberizasyon üzerindeki bu pozitif etkisi, ortamdaki etilenin (tuberizasyon için güçlü bir inhibitör) adsorbe edilmiş olabileceği ihtimali ile ilişkilendirilmiştir. Buna karşın, daha düşük konsantrasyonda aktif kömür sürgün oluşumunu artırmıştır (Lajayer ve ark. 2011).

Çalışmanın sonuçları özetlenecek olursa;

- JA'in ortama ilavesinin mikrotuber oluşumu üzerinde olumlu etki gösterdiği,

- Mikrotuberizasyon için en uygun fotoperiyodun sürekli karanlıkta inkübasyon olduğu,

- Mikrotuber oluşumu üzerinde agar konsantrasyonunun (\%0.5 ve \%0.7) etkileri arasında önemli bir farkın bulunmadı̆̆

- Aktif kömür katkısının mikrotuber oluşumunu JA’ten daha olumlu bir şekilde etkilediği,

- Aktif kömürün karanlıkta inkübasyonda daha etkili olduğu, JA ilave edilmiş ortamlardaki mikrotuber verimin ise kısa gün koşullarında daha iyi sonuç verdiği,

- In vitro koşullarda S. tuberosum L. cv. Marfona'nın mikrotuberizasyonu için en uygun ortam koşullarının; \%0.2 aktif kömür (AC) ve \%0.5 agar içeren çift fazlı MS besin ortamı ve sürekli karanlıkta inkübasyon olduğu belirlenmiştir.

Bundan sonraki çalışmalarda tuberizasyonu teşvik edici farklı maddelerin etkilerinin araştırılması, tohumluk mikrotuber üretim mekanizmasının geliştirilmesi açısından yararlı olacaktır.

\section{Kaynaklar}

Aslam A, Iqbal J (2010). Combined effect of cytokinin and sucrose on in vitro tuberization parameters of two cultivars, diamant and red norland of potato (Solanum tuberosum). Pakistan Journal of Botany, 42 (2): 1093-1102.

Beyazova S (1999). Production of microtubers in potato (Solanum tuberosum). Ortadoğu Teknik Üniversitesi Fen Bilimleri Enstitüsü, Yüksek Lisans Tezi, Ankara, 69s.

Bhatia AK, Pandita ML, Khurana SC (1992). Plant growth substances and sprouting conditions: II. Effect on tuber yield and multiplication rate in seed potato production. Journal of Indian Potato Association, 19: 154-156.

Burrows GE, Tyrl RJ (2001). Toxic plants of North America. Iowa State University Press, 1342 pp.

Carrera E, Bou J, Garcia- Martinez JL, Prat S (2000). Changes in GA 20-oxidase gene expression strongly affect stem length, tuber induction and tuber yield of potato plants. The Plant J., 22(3): 247-256.

Castro G, Guillermina A, Agüero C, Tizio R (2000). Interaction between jasmonic and gibberellic acids on in vitro microtuberization of potato plantlets. Potato Research, 43: 83-88.

Chevre AM, Gill SS, Mouras A, Salesses G (1983). In vitro vegetative multiplication of chestnut. The Journal of Horticultural Science and Biotechnology, 58: 23-29.

Garner N, Blake J (1989). The induction and development of potato microtubers in vitro on media free of growth regulating substances. Annals of Botany, 63: 663-674.

Hoque ME (2010). In vitro tuberization in potato (Solanum tuberosum L.). Plant Omics Journal, 3(1): 7-11.

Jackson SD, Willmitzer L (1994). Jasmonic acid spraying does not induce tuberization in short-dayrequiring potato species kept in non-inducing conditions. Planta, 194(2): 155-159.

Jackson SD (1999). Multiple signaling pathways control tuber induction in potato. Plant Physi., 119: 1-8.

Jasik J, Klerk GJ (2006). Effect of methyl jasmonate on morphology and dormancy development in lily bulblets regenerated in vitro. Journal of Plant Growth Regulation, 25: 45-51.

Jasik J, Mantell SH (2000). Effects of jasmonic acid and its methyl ester on in vitro microtuberization of three food yam (Dioscorea) species. Plant Cell Reports, 19: 863-867.

Kenar S (2013). Patateste (Solanum tuberosum L.) in vitro Mikrotuberizasyon Üzerine Jasmonik AsitGiberellik Asit Etkileşiminin Araştırılması. Hacettepe Üniversitesi, Fen Bilimleri Enstitüsü, Yüksek Lisans Tezi, Ankara, 74s.

Kenar S, Tipırdamaz R (2012). Patateste (Solanum tuberosum L.) in vitro mikrotuberizasyon üzerine bazı faktörlerin etkilerinin araştırılması, Kırgızistan Birinci Uluslararası Biyoloji Kongresi, 24-26 Eylül, Bişkek, Kırgızistan. 
Khuri S, Moorby J (1995). Investigations in to the role of sucrose in potato cv. Estima microtuber production in vitro. Annals of Botany, 75: 295-303.

Khuri S, Moorby J (1996). Nodal segments or microtubers as explants for in vitro microtuber production of potato. Plant Cell, Tissue and Organ Culture, 45: 215-222.

Kim SK, Kim JT, Jang SW, Lee SC, Lee BH, Lee IJ (2005). Exogenous effect of gibberellins and jasmoate on tuber enlargement of Dioscorea opposite. Agron Resource, 3: 39-44.

Lajayer HM, Esmaielpour B, Chamani E (2011). Hinokitiol and activated charcoal influence the microtuberization and growth of potato (Solanum tuberasum Cv. Agria) plantlets in vitro. Australian Journal of Crop Science, 5(11): 1481-1485.

Martinez-Garcia JF, Garcia-Martinez JL, Bou J, Prat S (2002). The interaction of gibberellins and photoperiod in the control of potato tuberization. Plant Growth Regulation, 20: 377-386.

Nistor A, Campeanu G, Atanasiu N, Chiru N, Karácsonyi D (2010). Influence of potato genotypes on "in vitro" production of microtubers. Romanian Biotechnological Letters, 15: 3.

Öztürk G (2003). Patateste (Solanum tuberosum L.) in vitro Koşullarda Mikro Yumru Üretimine Farklı Besin Ortamlarının Etkisi. Ege Üniversitesi Fen Bilimleri Ens., Yüksek Lisans Tezi, İzmir, $47 \mathrm{~s}$.

Phillips BJ, Hughes JA, Phillips JC, Walters DG, Anderson D, Tahourdin CSM (1996). A study of the toxic hazard that might be associated with the consumption of green potato tops. Food Chemistry and Toxicology, 34: 439-448.

Pierik RLM (1987). In Vitro Culture of Higher Plants. Martinus Nijhoff Publishers, Dordrecht, 344pp.

Pruski K, Duplessis P, Lewis T, Astatkie T, Nowak J (2001). Jasmonate effect on in vitro tuberization of potato (Solanum tuberosum L.) cultivars under light and dark conditions. Potato Res. 44: 315-325.

Pruski K, Duplessis P, Lewis T, Astatkie T, Nowak J, Struik PC (2002). Jasmonate effect on in vitro tuberization of potato (Solanum tuberosum L.) cultivars under light and dark conditions. Potato Research, 44: 315-325.

Ranalli P (1997). Innovative propagation methods in seed tuber multiplication programmes. Potato Research, 40: 439-453.

Rayirath UP, Lada RR, Caldwell CD, Asideu SK, Sibley KJ (2011). Role of ethylene and jasmonic acid on rhizome induction and growth in rhubarb (Rheum rhabarbaum L.). Plant Cell Tissue and Organ Culture, 105: 253-263.

Romanov GA, Aksenova NP, Konstantinova TN, Golyanovskaya SA, Kossman J, Willmitzer L (2000). Effect of indole-3-acetic acid and kinetin on tuberization parameters of different cultivars and transgenic lines of potato in vitro. Plant Growth Regulation, 32: 245-251.

Sangwan RS, Detrez C, Sangwan-Norreel BS (1987). In vitro culture of shoot-tip meristems in some higher plants. (Symposium on In Vitro Problems Related to Mass Propagation of Horticultural Plants. September 16-20, 1985), Acta Horticulturae 212: 661-667.

Seabrook JEA, Colpman S, Levy D (1993). Effect of photoperiod on in vitro tuberization of potato (Solanum tuberosum L.). Plant Cell, Tissue and Organ Culture, 34(1): 43-51.

Sokal R, Rohlf FJ (1995). Biometry, The Principles and Practice of Statistics in Biological Research, Third Edition, WH Freeman and Co, New York, USA, 859pp.

Taiz L, Zeiger E (2008). Bitki Fizyolojisi, 3. Baskı Çeviri (Çeviri editorü: Türkan İ), Palme Yayıncılık, Ankara.

Takahashi K, Fujino K, Kikuta Y, Koda Y (1994). Expansion of potato cells in response to jasmonic acid. Plant Science, 100: 3-8.

Tianyu Z, Junlian Z, Di W, Li W, Yansen C, Ximei D, Yuhui L, Youzhong L (2006). Study on the optimization of inducing potato microtuber system in different varieties. Chinese Agricultural Science Bulletin, 10.

Tican A, Chiru N, Ianosi M, Ivanovici DE, Sand C (2008). In vitro culture and micro / mini tubers behavior of Romanian potato varieties Christian and Roclas on microtubers production. 17th Triennial Conference of European Assocation Fot Potato Research, July 6-10, Braşov, Romania.

Vreugdenhil D, Xu X, Lammeren AAM (1998). Cell division and cell enlargement during potato tuber formation. Journal of Experimental Botany, 49: 320, 573-582.

Zhang Z, Zhou W (2005). The role of GA, IAA and BAP in the regulation of in vitro shoot growth and microtuberization in potato. Acta Physiologia Plantarum, 27(3B): 363-369.

Zhang ZJ, Li HZ, Zhou WJ, Takeuchi Y, Yoneyama K (2006). Effect of 5-aminolevulinic acid on development and salt tolerance of potato (Solanum tuberosum L.) microtubers in vitro. Plant Growth Regulation, 49: 27-34. 